\title{
Assessment of mechanisms of infectious pneumonia based on expression of fibrinogen, procalcitonin, high-sensitivity C-reactive protein expression, $T$ helper 17 cells, regulatory $T$ cells interleukin-10, and interleukin-17
}

\author{
Dao-Ming Zu, Lei Zhang \\ Department of Pediatrics, Pudong New Area Peoples' Hospital Affiliated to Shanghai University of Medicine and Health Sciences, Shanghai, China \\ Contributions: (I) Conception and design: DM Zu; (II) Administrative support: L Zhang; (III) Provision of study materials or patients: DM Zu; (IV) \\ Collection and assembly of data: DM Zu; (V) Data analysis and interpretation: DM Zu; (VI) Manuscript writing: Both authors; (VII) Final approval \\ of manuscript: Both authors. \\ Correspondence to: Lei Zhang. Pudong New Area Peoples' Hospital Affiliated to Shanghai University of Medicine and Health Sciences, No.490, South \\ Chuanhuan Road, Pudong, Shanghai, China. Email: taizhouzl68511@126.com.
}

\begin{abstract}
Background: Infectious pneumonia is one of the important causes of neonatal death that can lead to the imbalance of T helper 17 cells (Th17) and T regulatory T cells (Treg) cells. The correlation between plasma fibrinogen (FIB), procalcitonin (PCT), C-reactive protein (CRP) and Th17/Treg-IL-10/IL-17 axis balance and their specific role in the occurrence and development of infectious pneumonia are not completely clear.

Methods: Thirty specific-pathogen free Sprague Dawley (SD) rats were randomly divided into a control group for comparison and IPN model group. After the establishment of infectious pneumonia model, levels of FIB, PCT, hs-CRP, IL-10, and IL-17 in the serum of the two groups were measured using enzyme linked immunosorbent assay (ELISA), the pathological changes of lung tissue were observed using hematoxylin and eosin (HE) staining, the number of Treg and Th17 cells and the ratio of Th17/Treg in serum were detected using flow cytometry, and the levels of retinoic acid-related orphan receptor $\gamma t$ and forkhead box P3 (FOXP3) in lung tissue were detected using reverse transcription polymerase chain reaction (RT-PCR) and western blot. Results: The results showed that the serum levels of FIB, PCT, hs-CRP, Th17 cell number, Th17/Treg ratio, left lung dry and wet weight, lung tissue wet/dry ratio, lung pathology score and IL-17 level in the model group were significantly higher than those in the control group, while the number of Treg cells and the level of IL-10 in the model group were significantly lower than those in the control group. In addition, the expression of Foxp3mRNA and protein in lung tissue of model group decreased significantly, while the expression level of ROR- $\gamma \mathrm{t}$ mRNA and protein increased.

Conclusions: In infectious pneumonia, the expression levels of FIB, PCT and hs-CRP are up-regulated, and Th17 cells are activated, Treg cells are inhibited, proinflammatory cytokine IL-17 expression is up-regulated, anti-inflammatory cytokine IL-10 expression is down-regulated, resulting in increased inflammatory response, thus promoting the occurrence and development of infectious pneumonia.
\end{abstract}

Keywords: Fibrinogen (FIB); procalcitonin (PCT); high-sensitivity C-reactive protein (hs-CRP); T helper 17 cells (Th17); infectious pneumonia (IPN)

Submitted Oct 25, 2021. Accepted for publication Dec 30, 2021.

doi: $10.21037 / \mathrm{tp}-21-565$

View this article at: https://dx.doi.org/10.21037/tp-21-565 


\section{Introduction}

Infectious pneumonia (IPN) is a common disease in pediatrics, which is common in infants. The major infective sources for IPN include, for example, bacteria, viruses, fungi, and parasites, during delivery, and after birth and is accompanied by fever, cough, shortness of breath, and dyspnea (1). In severe cases, it can lead to a loss of appetite, dehydration, lethargy, and other symptoms. Its high incidence and rapid progress are important causes of death in children under five years old (2-4). Worldwide, two million children die of neonatal IPN every year, accounting for $5 \%$ to $35 \%$ of neonatal autopsies (5). As the initial clinical symptoms and signs of the disease are not obvious, the diagnosis is difficult, resulting in delay of the disease, resulting in a high mortality rate. Therefore, timely and accurate clinical diagnosis and treatment and disease monitoring are very important for the treatment of newborns.

In recent years, there are many studies on the pathogenesis of neonatal IPN, some studies have found that IPN is closely related to immune function, plasma fibrinogen (FIB), procalcitonin (PCT), and C-reactive protein (CRP), which in turn are closely related to the severity of pneumonia. PCT acts as the prohormone of calcitonin, reflecting the severity of infection. However, whether the PCT level is an ideal index to predict the prognosis of IPN remains debatable (6). CRP as first described by Tillet and Francis acts as an acute-phase protein (7) and is considered as also one of the important markers of pneumonia $(8,9)$. Neonatal IPN is often associated with other diseases, such as respiratory failure, septicemia, and meningitis (10). In addition, the abnormal activation of the inflammatory response in children with IPN is closely related to immune dysfunction. The pathological changes caused by viruses, bacteria, mycoplasma, and other pathogenic microorganisms infecting human tissues is a complex process, in which a variety of cytokines, especially Th1 and Th2 cells and their secreted cytokines, play an important role in regulating the host immune balance $(11,12)$. Studies have shown that after pathogenic microorganisms have invaded the human body, the immune function of the body is damaged, and the number and function of lymphocyte subsets are also affected, resulting in low immune function. This in turn promotes the occurrence and progression of infectious diseases and produces a series of pathological changes (13). Therefore, an assessment of the effect and mechanism of the inflammatory reaction and immune regulation in the context of IPN can provide new prospects for the diagnosis, treatment, and prognosis of IPN. We present the following article in accordance with the ARRIVE reporting checklist (available at https://tp.amegroups.com/article/ view/10.21037/tp-21-565/rc).

\section{Methods}

\section{Animals}

Sprague Dawley (SD) healthy male rats, weighing 200-230 g, were used in this study. The used SD rats were specificpathogen free. Five rats were raised in each cage at a constant temperature $\left(25 \pm 1{ }^{\circ} \mathrm{C}\right)$, humidity was $50-60 \%$, the dark/light cycle was 12 hours, and all rats were fed and drank water freely. The experiment began after adaptive feeding for 1 week. In the course of the experiment, the care and disposal of animals was strictly conformed to the "Guiding Opinions on Being Kind to Experimental Animals" issued by the Ministry of Science and Technology in 2006 (14), and the research has been approved by the Hospital Experimental Animal Ethics Committee (No. pry122020-013-a).

\section{Instruments and drugs}

Pseudomonas aeruginosa solution was purchased from Sigma-Aldrich (St. Louis, MO, USA); mouse anti-human interleukin-10 (IL-10), interleukin-17 (IL-17), retinoic acid-related orphan receptor $\gamma \mathrm{t}(\mathrm{ROR} \gamma \mathrm{t})$, forkhead box P3 (FOXP3) antibodies, and horseradish peroxidase (HRP) labeled sheep anti-rabbit immunoglobulin ( $\operatorname{IgG}$ ) second antibody were purchased from PeproTech (Rocky Hill, NJ, USA); FIB kits were purchased from Beijing Zhongshan Jinqiao Biology (Beijing, China); PCT kits were purchased from Beijing Zhongshan Jinqiao Biology (Beijing, China); high-sensitivity $\mathrm{C}$-reactive protein (hs-CRP) kits were purchased from Beijing Zhongshan Jinqiao Biology (Beijing, China); and hematoxylin and eosin (HE) staining kits were purchased from Semel Fisher Technology (Shanghai, China).

\section{Animal modeling and grouping}

Thirty male SD rats were randomly divided into a control group and a model group. The rats in the control group were given $0.6 \mathrm{~mL}$ normal saline as a nasal drip, while 
in the model group, the nostrils were tilted upward at 45 degrees after administration of anesthesia, and the $0.6 \mathrm{~mL}$ pseudomonas aeruginosa solution was administered into the nasal cavity with a microsampler to keep the rats upright for $1 \mathrm{~min}$ to ensure that the bacterial solution entered the trachea and bronchi. On the $5^{\text {th }}, 10^{\text {th }}$, and $15^{\text {th }}$ day following the intervention, the rats were killed under anesthesia, blood and bronchoalveolar lavage fluid (BALF) were collected, and lung tissue was quickly removed.

\section{Levels of FIB, PCT, and hs-CRP in serum of rats}

On the $5^{\text {th }}, 10^{\text {th }}$, and $15^{\text {th }}$ day after the intervention, blood samples were collected from the tail vein and centrifuged at 3,000 rpm for $10 \mathrm{~min}$. Plasma and serum were separated and cryopreserved at $-80{ }^{\circ} \mathrm{C}$. The level of plasma FIB was measured using an automatic hemagglutination analyzer, the level of serum PCT was determined using an electrochemiluminescence instrument, and the level of serum hs-CRP was determined using immune scattering turbidimetry. All tests were carried out according to the relevant instructions of the kits. The normal reference ranges of serum FIB, PCT, and hs-CRP are as follows: PCT: $0-0.5 \mu \mathrm{g} / \mathrm{mL}$; FIB: $0-80 \mathrm{ng} / \mathrm{mL}$; and hs-CRP: $0-8 \mathrm{mg} / \mathrm{mL}$.

\section{Isolation of rat peripheral blood mononuclear cells (PBMC)}

The rats were anesthetized with $10 \%$ chloral hydrate, and blood was collected from the abdominal aorta. The blood was added to a centrifuge tube containing $6 \mathrm{~mL}$ separation solution, centrifuged 20-30 min, and the second layer of annular milky white lymphocyte layer was carefully absorbed with a straw and transferred to another centrifuge tube. Following $350 \mathrm{~g} \times 10 \mathrm{~min}$ centrifugation, twice washing with an appropriate amount of PBS solution, centrifugation, and discarding of the PBS solution, RPMI1640 culture solution was used to resuspend PBMS.

\section{Isolation of Treg cells from rat peripheral blood and flow antibody staining}

Three hundred $\mu \mathrm{L}$ cell suspension were placed into an Eppendorf tube and incubated at $37^{\circ} \mathrm{C}$ for $10 \mathrm{~h}$. Then, the suspension was transferred to the flow tube, $100 \mu \mathrm{L}$ staining buffer resuspension cells were added, and $5 \mu \mathrm{L}$ surface antibodies (CD4-PerCP-Cyanine5.5 and CD25FITC) were added and mixed well. The incubation period was 20-30 min at room temperature without light. Two $\mu \mathrm{L}$ precooled staining buffer were added and centrifuged with $550 \mathrm{~g} \times 6 \mathrm{~min}\left(2-8{ }^{\circ} \mathrm{C}\right)$. One $\mathrm{mL}$ FIX \& PERM (fixed membrane breaker, Thermo Fisher, Waltham, MA, USA) were added and left for $40-50 \mathrm{~min}$ away from light at $2-8^{\circ} \mathrm{C}$, then centrifuged with $1 \mathrm{~mL}$ cell lotion (repeated three times), the supernatant was discarded, $80 \mu \mathrm{L}$ cell wash solution was added, intracellular antibody (Human Foxp3 Buffer Set, BD Biosciences, San Jose, CA, USA) was added and mixed well, and then allowed to rest 40-50 min away from light at $2-8{ }^{\circ} \mathrm{C}$. Following this, $2 \mathrm{~mL}$ cell lotion was added, and then the mixture was centrifuged to remove the supernatant (repeated twice). Then add $350 \mu \mathrm{L}$ pre-cooled Staining Buffer and detect it on machine.

\section{Isolation of T belper 17 cells (Tb17) cells from rat peripheral blood and flow antibody staining}

The $300 \mu \mathrm{L}$ cell suspension was placed into an EP tube, and $4 \mu \mathrm{L}$ Leukocyte Activation Cocktail (leukocyte stimulant, BD Biosciences, San Jose, CA, USA) were added according to the procedure of "peripheral blood Treg cell separation and flow antibody staining". The intracellular antibody was IL-17A-APC, and the number of Th17 cells in peripheral blood was detected.

\section{Detection of the ratio of Th17 and Treg cells to $\mathrm{CD}^{+} \mathrm{T}$ lymphocytes in peripheral blood by flow cytometry}

Flow cytometry is a tool that rapidly analyzing multiparametric single cells or particles in solution. It is also a powerful technology applied in infectious disease monitoring (15). Therefore, in this study, flow cytometry was used to detect the fluorescence intensity of CD4, Foxp3, and IL-17 in peripheral blood T lymphocytes. The lymphocyte population was determined using forward angular scattering light (FCS) and lateral angular scattering light (SSC), and then $\mathrm{CD}^{+}$and Foxp $3^{+} \mathrm{IL}-17^{+}$ dual gates were set. The percentage of Th17 and Treg was calculated as the ratio of $\mathrm{CD}^{+}{ }^{+} \mathrm{Foxp}^{+} \mathrm{T}$ lymphocytes to $\mathrm{CD}^{+}{ }^{+} \mathrm{T}$ lymphocytes (Treg/CD $4 \%$ ) and CD $4+\mathrm{IL}-17^{+} /$ $\mathrm{CD}^{+}{ }^{+} \mathrm{T}$ lymphocytes (IL-17/CD $4^{+} \%$ ), and the results were represented as a two-dimensional dot-plot scatter map and analyzed using CellQuest software (BD Biosciences, San 
Table 1 Reverse transcription polymerase chain reaction primer sequence table

\begin{tabular}{llc}
\hline Signal path & Primer sequence (5'-3') & Amplified fragment (bp) \\
\hline RORyt & F 5'-TGC GAC TGG AGG ACC TTC TA-3' & 270 \\
& R 5'-AGA CTG TGT GGT TGT TGG CA-3' & 122 \\
FOXP3 & F 5'- ATG TTC GCC TAC TTC AGA A-3' & 375 \\
& R 5'-TCA TCT ACG GTC CAC ACT-3' & 3 \\
GADPH & F 5'-GCC ATG TAC GTA GCC ATC CA-3' & \\
\hline
\end{tabular}

ROR $\gamma \mathrm{t}$, retinoic acid-related orphan receptor $\gamma \mathrm{t}$; FOXP3, forkhead box P3; GADPH, glyceraldehyde 3-phosphate dehydrogenase.

Jose, CA, USA).

\section{Observation of pathological changes of lung tissue using HE staining}

After bronchoalveolar lavage, the mice were dissected to expose the chest, the tissue of the lower lobe of the right lung was quickly stripped, the blood stains were washed with precooled normal saline, and then fixed in precooled $4 \%$ paraformaldehyde solution for at least 24 hours. Paraffin sections were prepared in a series of steps including dehydration, embedding, and slicing. Then, routine HE staining was performed to visualize the inflammatory changes of bronchi and blood vessels in lung tissue under a microscope.

\section{Collection of BALF}

After intraperitoneal injection of sodium pentobarbital anesthesia, an incision was made at a suitable position of the trachea, the left lung with the trachea was taken out, the right bronchus was ligated, $3 \mathrm{~mL}$ normal saline at $4{ }^{\circ} \mathrm{C}$ were injected into the trachea for left lung lavage, and the operation was repeated 3 times to obtain BALF, the BALF was centrifuged at $1,500 \mathrm{r} / \mathrm{min}^{-1}$ at $4{ }^{\circ} \mathrm{C}$ for $10 \mathrm{~min}$, and the supernatant was stored in a refrigerator at $-80^{\circ} \mathrm{C}$ for later use.

\section{Detection of IL-10 and IL-17 in serum and BALF using enzyme linked immunosorbent assay (ELISA)}

The blood and BALF were centrifuged, and the upper serum and BALF were collected and stored in $-20{ }^{\circ} \mathrm{C}$ refrigerator, and the levels of IL-10 and IL-17 in serum and BALF were detected adhering strictly to the procedure of the ELISA kit.

\section{Detection of RORyt and FOXP3 mRNA expression by reverse transcription polymerase chain reaction (RT-PCR) method}

Total RNA was extracted from lung tissue, and the purity of RNA was detected at $260 \mathrm{~nm}$ using an ultraviolet spectrophotometer. Reverse transcription and real-time fluorescence quantitative PCR reaction were carried out according to the steps of reverse transcription described in the PCR kit (Table 1). The PCR reaction conditions were as follows: $94^{\circ} \mathrm{C}$ predenatured for $5 \mathrm{~min}, 10 \mathrm{~min}$ 40 times $\left(96^{\circ} \mathrm{C}\right.$ denatured $30 \mathrm{~s}, 60^{\circ} \mathrm{C}$ annealing $40 \mathrm{~s}, 72{ }^{\circ} \mathrm{C}$ extension $1 \mathrm{~min}), 72{ }^{\circ} \mathrm{C}$ extension $10 \mathrm{~min}$. $\beta$-actin was the internal reference. The PCR products were analyzed using electrophoresis on Agar gel, and the PCR results were analyzed using OpticonMonitor3 software (Bio-Rad, Hercules, CA, USA). After repeating the experiment three times, the average value was calculated, the ROR $\gamma \mathrm{t} / \mathrm{FOXP} 3$ ratio was calculated, whereby the $\mathrm{ROR} \gamma \mathrm{t} / \mathrm{FOXP} 3$ ratio represented the Th17/Treg level.

\section{Detection of RORyt and FOXP3 protein expression using western blot}

After stripping the right lung, the right lung was added to the precooled lysate at $4{ }^{\circ} \mathrm{C}$. The volume ratio of lung tissue to lytic fluid was $1: 10$, cryopreserved for $1 \mathrm{~h}$, and all the lysates were collected. The corresponding tissue protein was extracted using tissue protein extraction kit, and the concentration of protein was detected using the bicinchoninic acid (BCA) method, and a protein tissue sample containing the same amount of protein was prepared. After adding the protein sample buffer and boiling, a $12 \%$ sodium dodecyl sulphate-polyacrylamide gel electrophoresis (SDS-PAGE) gel was prepared for electrophoresis, and the semi-dry film 

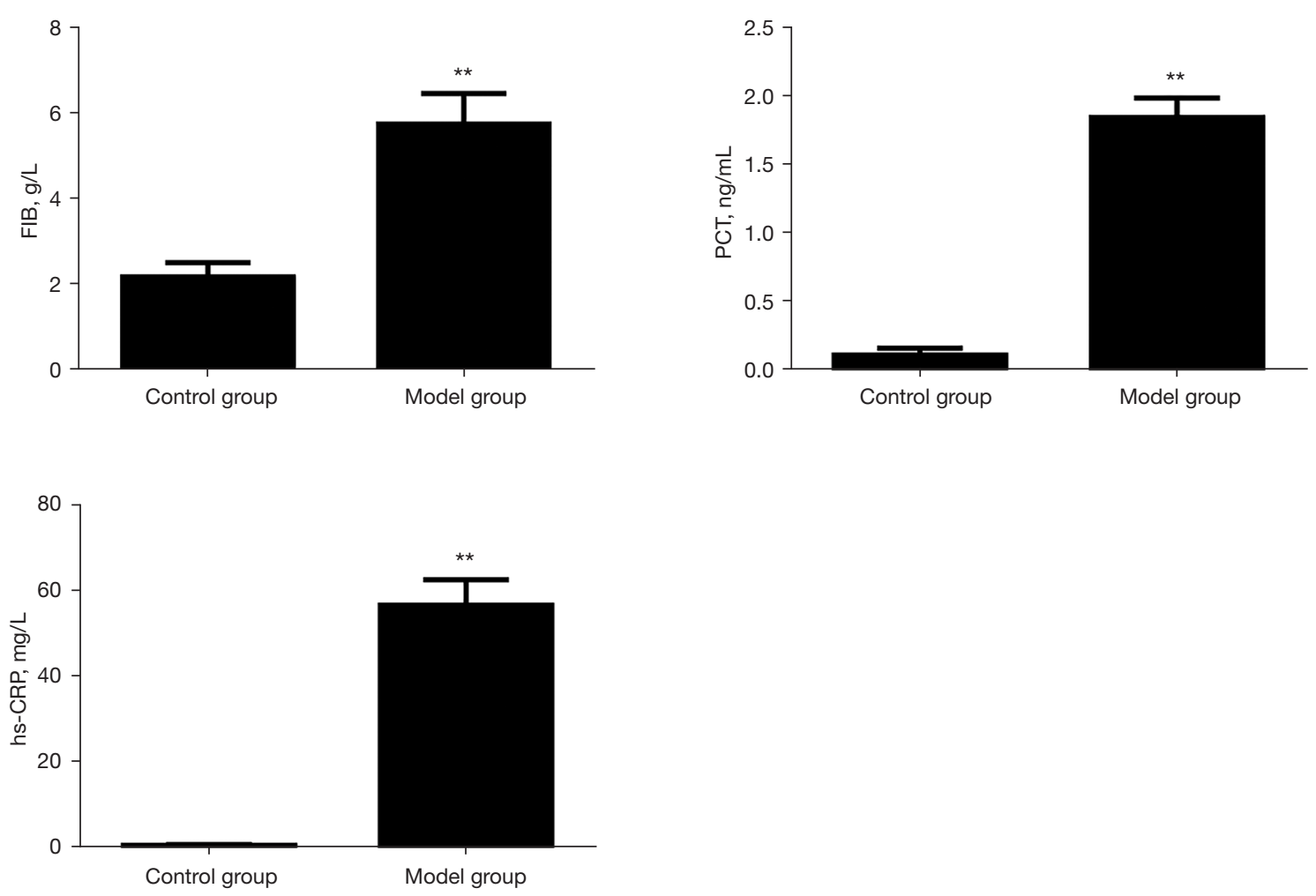

Figure 1 Comparison of serum FIB, PCT, and hs-CRP levels in rats $\left(\bar{x} \pm\right.$ s). Compared with the blank control group. ${ }^{* *}$, refers to $\mathrm{P}<0.01$. FIB, fibrinogen; PCT, parathyroid calcitonin; hs-CRP, high-sensitivity C-reactive protein.

rotation instrument was used to transfer the membrane. Chemiluminescence detection Quantity One software (BioRad, Hercules, CA, USA) was used to analyze the image, calculate the expression level of ROR $\gamma \mathrm{t}$ and FOXP3, and calculate the ratio of ROR $\gamma \mathrm{t} / \mathrm{FOXP}$, whereby the ratio of ROR $\gamma \mathrm{t} / \mathrm{FOXP} 3$ represents the level of Th17/Treg.

\section{Statistical methods}

All the data in this study were processed using SPSS version 20.0 statistical analysis software (SPSS Inc., Chicago, IL, USA). Measurement data are presented as mean \pm standard deviation $(\bar{x} \pm \mathrm{S})$, and the comparisons between groups were analyzed using one-way analysis of variance (ANOVA). If there was a difference in the mean value of the groups, the Newman-Keuls method was used to compare the mean value between groups, and $\chi^{2}$ analysis was used to compare discrete data and percentages (\%) to present such data.

\section{Results}

Comparison of serum FIB, PCT, and hs-CRP levels in rats

Compared with the blank control group, the serum levels of FIB, PCT, and hs-CRP in the model group were significantly higher than those in the control group $(\mathrm{P}<0.01)$. The results are shown in Figure 1.

\section{Comparison of Th17 and Treg cells and Th17/Treg ratio in peripheral blood of rats}

Compared with the blank control group, the number of Th17 cells in the model group was significantly increased, the number of Treg cells was significantly decreased, the Th17/Treg ratio was significantly increased, and the 
A
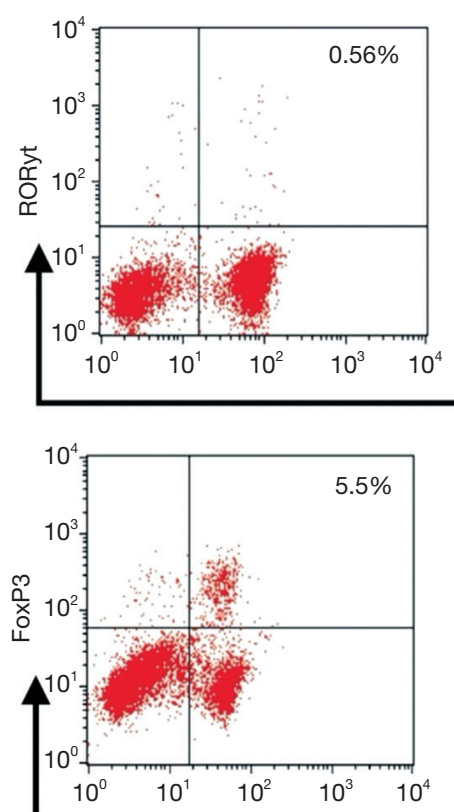

B
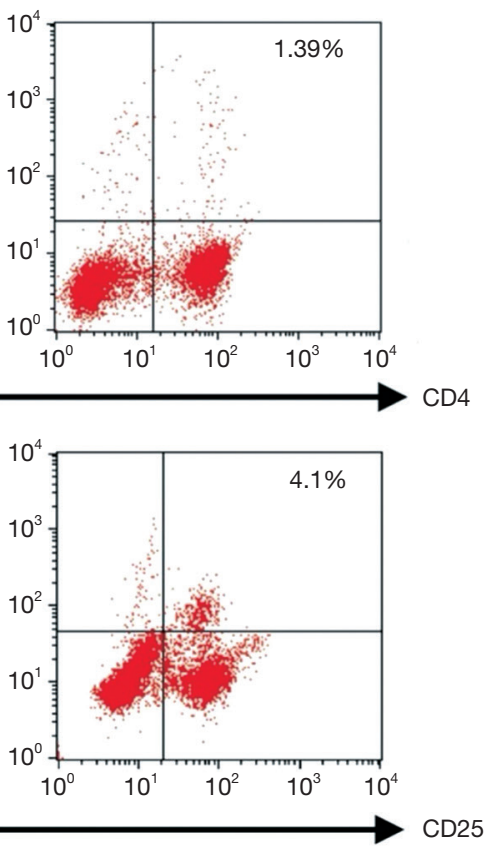

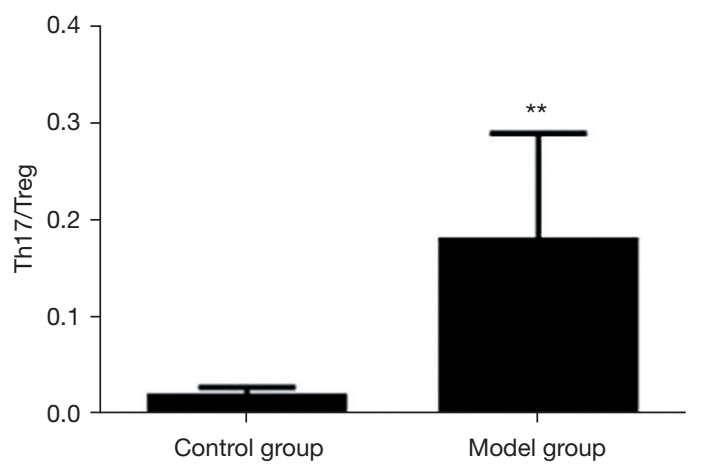

Figure 2 Comparison of Th17 and Treg cells and Th17 and Treg ratio in peripheral blood of rats ( $\bar{x} \pm \mathrm{s})$. Compared with the blank control group. ${ }^{*}$, refers to $\mathrm{P}<0.01$. FOXP3, forkhead box; ROR $\gamma t$, retinoic acid-related orphan receptor $\gamma t$; Th17, T helper 17 cells; Treg, regulatory T.

difference was statistically significant $(\mathrm{P}<0.01)$. The results are shown in Figure 2.

\section{Comparison of dry and wet weight of rat lung tissue}

Compared with the blank control group, the left lung wet weight, dry weight, and lung tissue wet/dry ratio in the model group increased significantly, and the difference was statistically significant $(\mathrm{P}<0.01)$. The results are shown in Figure 3.

\section{Comparison of pathological changes and pathological scores of rat lung tissues}

In the blank control group, the structure of alveolar epithelial cells was complete, the alveolar cavity was clear, and no inflammatory cell infiltration was seen; in the model control group, focal alveolar wall widening, varying thickness, alveolar septal capillary congestion, edema, lymphocytes, and monocytes were seen infiltrating the cells, and there was no exudate in the alveolar cavity, the alveoli were of different sizes, and there was fusion. Compared with the blank control group, the lung tissue pathology score of the model group was significantly increased, and the difference was statistically significant $(\mathrm{P}<0.05)$. The results are shown in Figure 4.

\section{Comparison of IL-10 and IL-17 levels in serum and BALF of rats}

Compared with the blank control group, the IL-17 level of the model group was significantly increased, while the IL10 level was significantly decreased, and the difference was statistically significant $(\mathrm{P}<0.01)$. The results are shown in Figure 5.

\section{Changes of RORyt and FOXP3mRNA in rat lung tissue}

Compared with the blank control group, Foxp3 mRNA in the lung tissue of the model group was significantly reduced, while the level of ROR- $\gamma \mathrm{t}$ mRNA was increased, and the difference was statistically significant $(\mathrm{P}<0.01)$. The results are shown in Figure 6.

\section{Comparison of the expression levels of ROR $\mathrm{Rt}$ and FOXP3 protein in rat lung tissue}

Compared with the blank control group, the expression of 

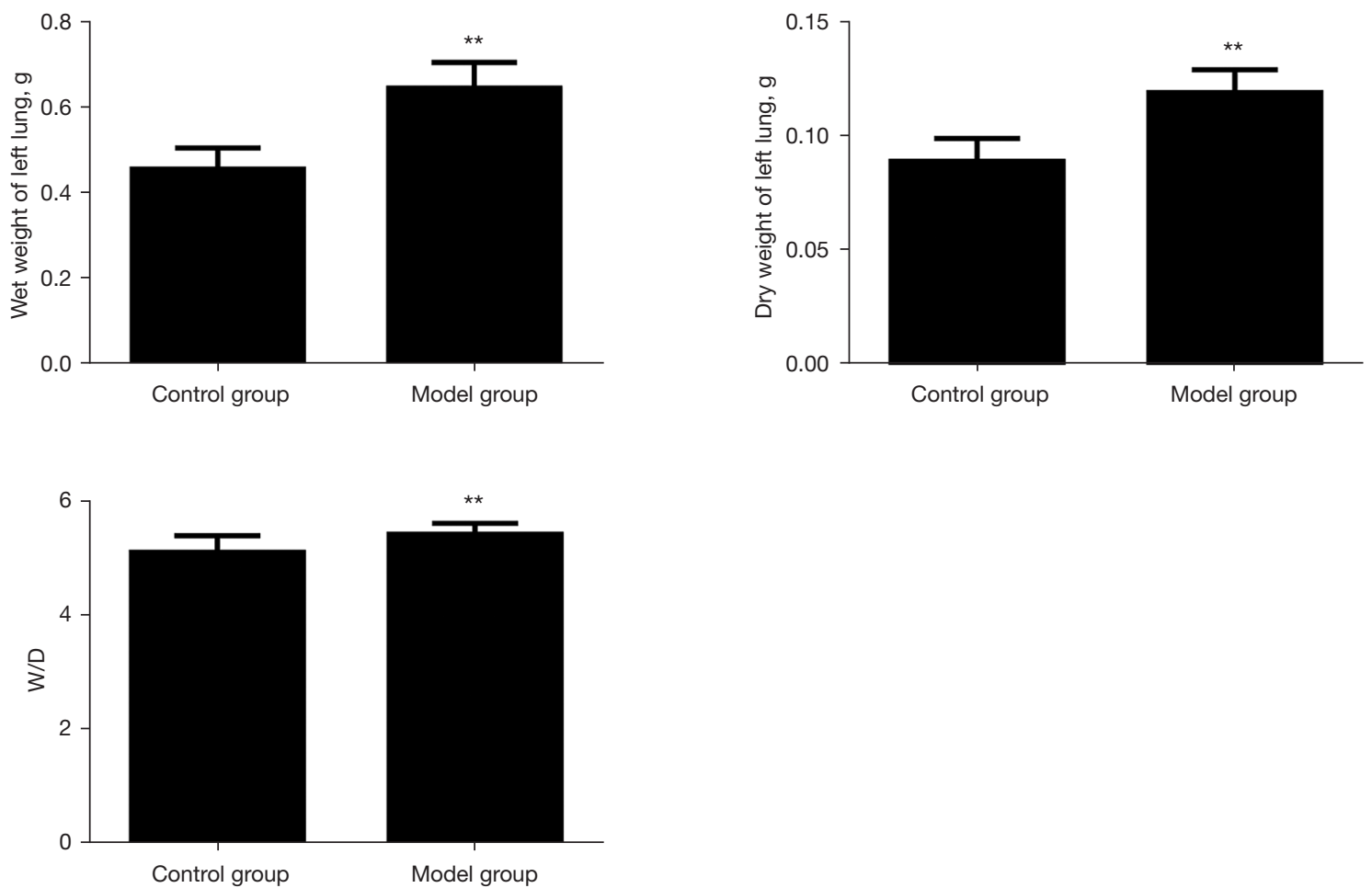

Figure 3 Comparison of dry and wet weight of rat lung tissue $(\bar{x} \pm s)$. Compared with the blank control group. ${ }^{* *}$, refers to $\mathrm{P}<0.01$. W/D, wet weight/dry weight of lung tissue ratio.

FOXP3 protein in the lung tissue of the model group was significantly reduced, while the expression level of ROR$\gamma \mathrm{t}$ protein was increased, and the difference was statistically significant $(\mathrm{P}<0.01)$. The results are shown in Figure 7.

\section{Discussion}

With the increase in air pollution, the incidence of respiratory diseases has been increasing year by year in recent years, especially in children, whose organs and immune functions are not yet well developed. As such, it is difficult for the body to resist the invasion of various pathogenic bacteria, and therefore, IPN has become the primary cause of hospitalization in this group (16). Because the occurrence and progression of IPN is characterized by special pathophysiological mechanisms, the immune status, clinical manifestations, distributions of pathogenic microorganisms, and disease outcomes of children are different from those of adults IPN (17). Therefore, clinical diagnosis and treatment are more difficult, and the prognosis of children is poor. At present, drug sensitivity tests and blood pathogen culture are the main basis for the diagnosis of IPN, but the disease progresses rapidly, and this method takes a long time, which is not conducive to timely and effective treatment of patients (18). Therefore, effective and sensitive diagnostic indicators are of great significance to improve the cure rate of IPN.

FIB is a dimer glycoprotein in the blood, which reacts to coagulation in the acute phase and is mainly produced and secreted by the liver. To date, many clinical studies have been conducted on the hemodynamics and coagulation function of the body (19). FIB can be used as a cofactor of platelet aggregation, and it increases to varying degrees in various diseases such as diabetes, pregnancy-induced hypertension, acute glomerulonephritis, and cancer (20). It has also been demonstrated that the expression of FIB is upregulated in infectious diseases, which in turn is accompanied by an increasing trend of inflammatory reaction (21). Studies have found that when the body is seriously infected, patients show blood coagulation dysfunction, and FIB and other related blood coagulation function indicators may indicate pneumonia (22). Serum PCT is secreted by human thyroid C cells and is a glycoprotein involved in the process of infection, the active 

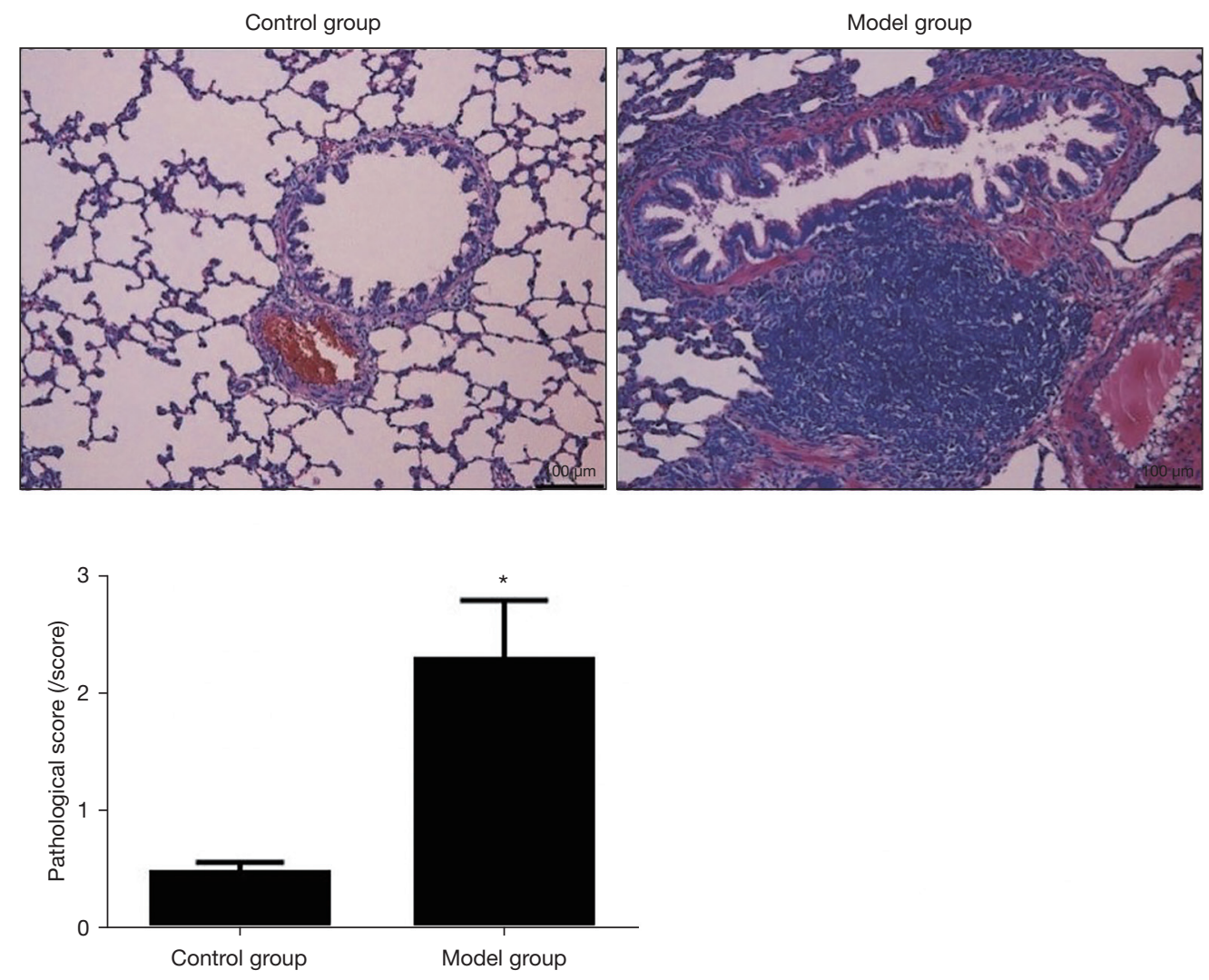

Figure 4 Comparison of pathological changes and pathological scores of rat lung tissues $(\bar{x} \pm \mathrm{s})$. Compared with the blank control group. *, refers to $\mathrm{P}<0.05$. The pathological changes of lung tissue were observed using HE staining. HE, hematoxylin and eosin.

components are hydrolyzed to form active components, and the content of PCT in normal people is low. As such, only a very small number of PCT can be released into the blood through a variety of cells, and generally the level of serum PCT cannot be detected, or its concentration is very low $(23,24)$. When systemic infection occurs, especially bacterial infection, a large amount of PCT is released into the blood, and the concentration of PCT in serum increases, and there are differences in different pathogens. As such, it can be used in the differential diagnosis of tissue infection, disease severity, disease dynamic changes, and, to a certain extent, the prognosis of different pathogens $(25,26)$. hs-CRP is a type of reactive protein, which reflects human acute infection, plays a unique role in innate immunity and adaptive immunity with inflammatory effect, and is considered to be the earliest objective index to determine bacterial infection $(27,28)$. It has been reported that all infections, stress reactions, autoimmunity, and tumor diseases may lead to an increase of serum CRP, while the upregulation of CRP expression can induce the expression of IL-6, IL-1 $\beta$, and tumor necrosis factor $\alpha$ (TNF- $\alpha)(29,30)$. The results of this study demonstrated that compared with the blank control group, the serum levels of FIB, PCT, and hs-CRP in the model group were significantly increased.

Th17 and Treg cells are the key immune cells that regulate the body's immune tolerance $(31,32)$. Th17 cells are characterized by CD4 $\mathrm{T}$ cells, which produce IL-17, IL-21, IL-22, and IL-26, and are a new proinflammatory $\mathrm{T}$ helper cell subset (33). Treg is a type of $\mathrm{T}$ cell subgroup, which negatively regulates the activation and proliferation of $\mathrm{T}$ lymphocytes. The loss of these cells can lead to the occurrence of a variety of organ-specific and non-organ-specific autoimmune diseases, and the process of maintaining immune homeostasis plays a vital role (34). During the development of IPN, Th1 and Th17 are significantly activated, and the cytokines they secrete can cause tissue damage while clearing pathogens. The activation of Th2 and Treg can inhibit the function of Th1 and Th17 after the pathogen is cleared and prevent tissue damage (35). The results of this study demonstrate that, 

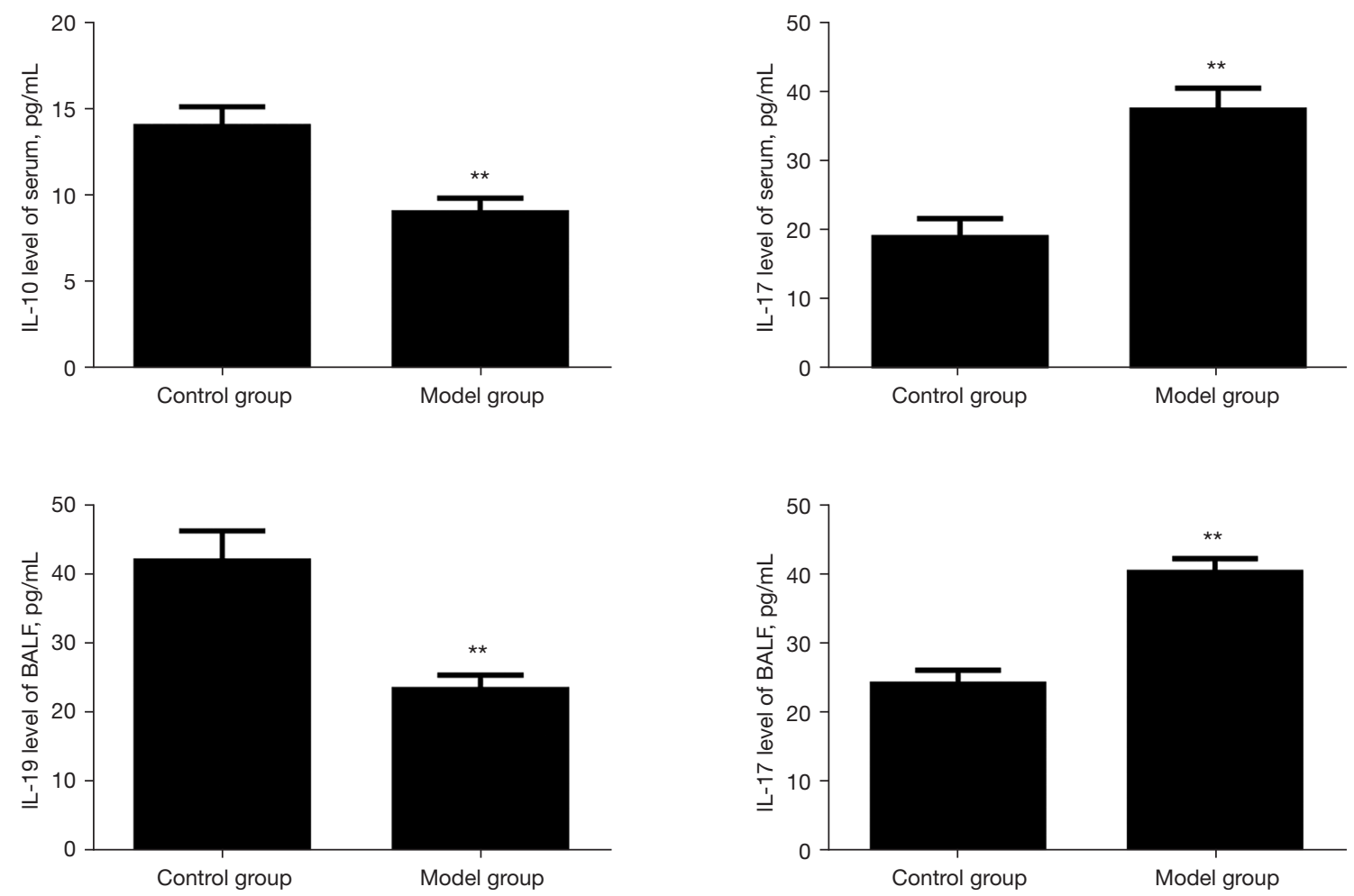

Figure 5 Comparison of IL-10 and IL-17 levels in serum and blood and BALF of rats $(\bar{x} \pm \mathrm{s})$. Compared with the blank control group. **, refers to $\mathrm{P}<0.01$. IL, interleukin; BALF, bronchoalveolar lavage fluid.

compared with the blank control group, the number of Th17 cells, Th17/Treg ratio, and IL-10 levels in the model group were significantly increased, while the number of Treg cells and IL-10 levels were significantly reduced.

Retinoic acid-related orphan nuclear receptor C (RORc) encodes a human homologue of mouse ROR $\gamma t$. It is a key nuclear factor for Th17 cell differentiation and a specific transcriptional activator for Th17 cell lineage, can induce and regulate Th17 cells to secrete high levels of IL-17, accelerate the aggravation of airway remodeling and airway mucus secretion, and aggravate airway inflammatory response (36). Forkhead box P3 (Foxp3) is a transcription factor encoded on $\mathrm{X}$ chromosome, it belongs to the family of forkhead box, FOX transcription factors and has a highly conserved DNA binding domain (37). Under physiological or pathological conditions, Foxp3 is a marker molecule of regulatory T cells (Treg). Foxp3 gene mutation can cause serious autoimmune diseases, and discovery of $F O X P 3$ gene is an important progress in Treg immunobiology and opens a door for people to further understand the function and mechanism of Treg (38). Th17 and Treg inhibit each other in differentiation and function, and their differentiation and maturation are mainly regulated by their upstream transcription factors ROR $\gamma \mathrm{t}$ and FOXP3. ROR $\gamma \mathrm{t}$ and FOCP3 restrict each other and jointly maintain the balance of Th17 and Treg cells. The results of this study show that, compared with the blank control group, the expression of FOXP3 mRNA and protein in the lung tissue of the model group was significantly reduced, while the expression levels of ROR $\gamma \mathrm{t}$ mRNA and protein increased.

In order to better study the pathogenesis of infectious pneumonia, the experimental animal model has become an indispensable research tool for researchers. The advantage of the experimental animal model is that it can't only design the experimental purpose and strategy in advance. As far as possible to eliminate the factors that may interfere with the reliability of the experimental results, but also can carry out experimental operations that can't be carried out in patients but are very important, however, due to some species differences between animals and humans, some results can't be directly used in clinical guidance. The results of this study provide a theoretical basis for the effect of the Th17, Treg-IL-10, and IL-17 axis balance on the incidence of IPN. To clarify the role of the Th17, Treg-IL-10, and IL- 

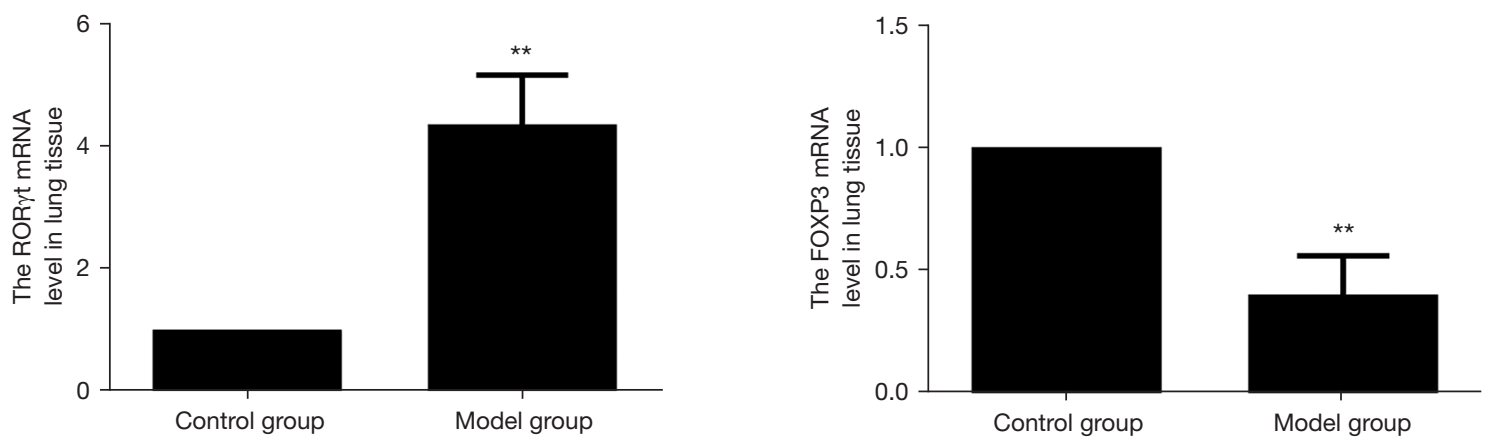

Figure 6 Changes of ROR $\gamma t$ and FOXP 3 mRNA in rat lung tissue $(\bar{x} \pm s)$. Compared with the blank control group. **, refers to $\mathrm{P}<0.01$. ROR $\gamma \mathrm{t}$, retinoic acid-related orphan receptor $\gamma \mathrm{t}$; FOXP3, forkhead box P3; mRNA, messenger RNA.
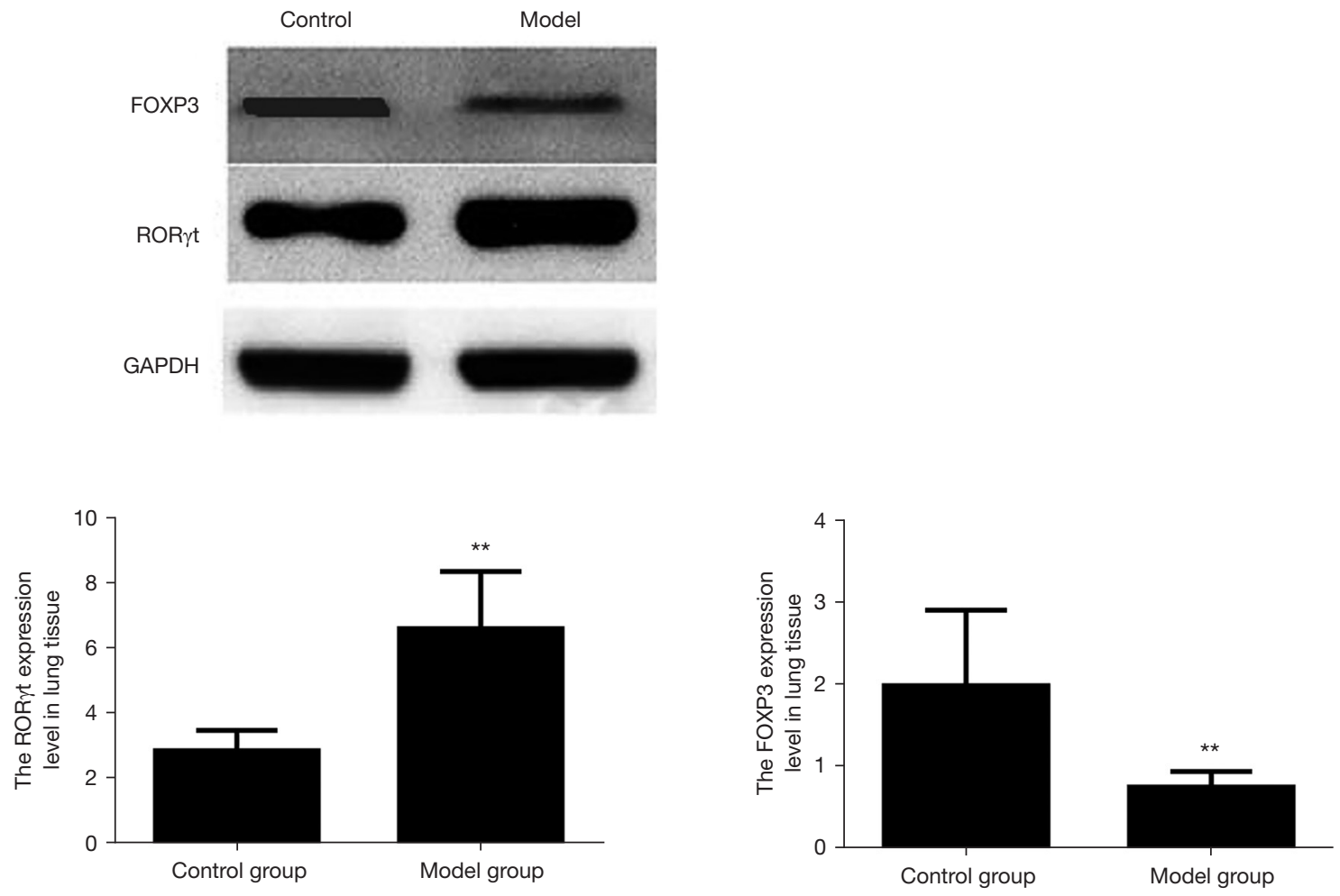

Figure 7 Comparison of the expression levels of ROR $\gamma$ t and FOXP3 protein in rat lung tissue ( $\bar{x} \pm \mathrm{s})$. Compared with the blank control group. **, refers to $\mathrm{P}<0.01$. ROR $\gamma$ t, retinoic acid-related orphan receptor $\gamma \mathrm{t}$; FOXP3, forkhead box $\mathrm{P} 3$.

17 axis balance in patients with IPN, it is still necessary to analyze the relevant indicators of clinical cases.

\section{Acknowledgments}

Funding: This study was supported by a General Project Grant from the Pudong Health Commission of Shanghai
(Grant No. PW2020A-71).

\section{Footnote}

Reporting Checklist: The authors have completed the ARRIVE reporting checklist. Available at https:// tp.amegroups.com/article/view/10.21037/tp-21-565/rc 
Data Sharing Statement: Available at https://tp.amegroups. com/article/view/10.21037/tp-21-565/dss

Conflicts of Interest: Both authors have completed the ICMJE uniform disclosure form (available at https://tp.amegroups. com/article/view/10.21037/tp-21-565/coif). The authors have no conflicts of interest to declare.

Ethical Statement: The authors are accountable for all aspects of the work in ensuring that questions related to the accuracy or integrity of any part of the work are appropriately investigated and resolved. In the course of the experiment, the care and disposal of animals was strictly conformed to the "Guiding opinions on being kind to experimental animals" issued by the Ministry of Science and Technology in 2006, and the research has been approved by the Hospital Experimental Animal Ethics Committee (No. pry122020-013-a).

Open Access Statement: This is an Open Access article distributed in accordance with the Creative Commons Attribution-NonCommercial-NoDerivs 4.0 International License (CC BY-NC-ND 4.0), which permits the noncommercial replication and distribution of the article with the strict proviso that no changes or edits are made and the original work is properly cited (including links to both the formal publication through the relevant DOI and the license). See: https://creativecommons.org/licenses/by-nc-nd/4.0/.

\section{References}

1. Hooven TA, Polin RA. Pneumonia. Semin Fetal Neonatal Med 2017;22:206-13.

2. Cillóniz C, Torres A, Niederman M, et al. Communityacquired pneumonia related to intracellular pathogens. Intensive Care Med 2016;42:1374-86.

3. Neill S, Dean N. Aspiration pneumonia and pneumonitis: a spectrum of infectious/noninfectious diseases affecting the lung. Curr Opin Infect Dis 2019;32:152-7.

4. Dulek DE, Mueller NJ; AST Infectious Diseases Community of Practice. Pneumonia in solid organ transplantation: Guidelines from the American Society of Transplantation Infectious Diseases Community of Practice. Clin Transplant 2019;33:e13545.

5. Huber BM, Meyer Sauteur PM, Unger WWJ, et al. Vertical Transmission of Mycoplasma pneumoniae Infection. Neonatology 2018;114:332-6.

6. Bloos F, Marshall JC, Dellinger RP, et al. Multinational, observational study of procalcitonin in ICU patients with pneumonia requiring mechanical ventilation: a multicenter observational study. Crit Care 2011;15:R88.

7. Tillett WS, Francis T. Serological reactions in pneumonia with a non-protein somatic fraction of pneumococcus. J Exp Med 1930;52:561-71.

8. Hopstaken RM, Cals JW, Dinant GJ. Accuracy of lipopolysaccharide-binding protein (LBP) and fibrinogen compared to C-reactive protein (CRP) in differentiating pneumonia from acute bronchitis in primary care. Prim Care Respir J 2009;18:227-30.

9. Smilowitz NR, Kunichoff D, Garshick M, et al. C-reactive protein and clinical outcomes in patients with COVID-19. Eur Heart J 2021;42:2270-9.

10. Radera S, Tripathi S, Agarwal J, et al. Chryseobacterium Indologenes-Associated Pneumonia in 2 Neonates. Pediatr Infect Dis J 2017;36:337-9.

11. Gong L, Xu L, Diao M, et al. Clinical effect of treating secondary asthma attacks of children Mycoplasma pneumoniae with combined therapy of montelukast and azithromycin. Eur Rev Med Pharmacol Sci 2016;20:5256-60.

12. Raphael I, Nalawade S, Eagar TN, et al. T cell subsets and their signature cytokines in autoimmune and inflammatory diseases. Cytokine 2015;74:5-17.

13. Xu Z, Hu W, Tong S. Temperature variability and childhood pneumonia: an ecological study. Environ Health 2014;13:51.

14. Notice regarding the issuance of the "Guiding Opinions on the Good Treatment of Laboratory Animals" (Guoke Fa Cai Zi [2006] No. 398). Available online: http:// www.most.gov.cn/xxgk/xinxifenlei/fdzdgknr/fgzc/gfxwj/ gfxwj2010before/201712/t20171222_137025.html, last access on 28 December 2021.

15. Vanhauteghem D, Audenaert K, Demeyere K, et al. Flow cytometry, a powerful novel tool to rapidly assess bacterial viability in metal working fluids: Proof-of-principle. PLoS One 2019;14:e0211583.

16. Zhang Z, Chai P, Wang J, et al. Association of particulate matter air pollution and hospital visits for respiratory diseases: a time-series study from China. Environ Sci Pollut Res Int 2019;26:12280-7.

17. Mathur NB, Murugesan A. Comparison of Four Days Versus Seven Days Duration of Antibiotic Therapy for Neonatal Pneumonia: A Randomized Controlled Trial. Indian J Pediatr 2018;85:963-7.

18. Yun KW, Wallihan R, Juergensen A, et al. CommunityAcquired Pneumonia in Children: Myths and Facts. Am J 
Perinatol 2019;36:S54-7.

19. Ko YP, Flick MJ. Fibrinogen Is at the Interface of Host Defense and Pathogen Virulence in Staphylococcus aureus Infection. Semin Thromb Hemost 2016;42:408-21.

20. Ueki R, Liu L, Kashiwagi S, et al. Role of Elevated Fibrinogen in Burn-Induced Mitochondrial Dysfunction: Protective Effects of Glycyrrhizin. Shock 2016;46:382-9.

21. Li T, Yu H, Hou W, et al. Evaluation of variation in coagulation among children with Mycoplasma pneumoniae pneumonia: a case-control study. J Int Med Res 2017;45:2110-8.

22. Min W, Zi-Feng J, Jian-Lin X, et al. Role of the Fibrinogen Degradation Products and D-Dimer in the Differential Diagnosis of Pulmonary Tuberculosis and Community-Acquired Pneumonia. Clin Lab 2018;64:135-40.

23. Wang HL, Li YL, Li XF, et al. The value of serum procalcitonin in the anti-infection therapy of acute stroke patients. Pak J Med Sci 2021;37:1155-60.

24. Niu D, Huang Q, Yang F, et al. Serum biomarkers to differentiate Gram-negative, Gram-positive and fungal infection in febrile patients. J Med Microbiol 2021. doi: 10.1099/jmm.0.001360.

25. Gilbert DN. Role of Procalcitonin in the Management of Infected Patients in the Intensive Care Unit. Infect Dis Clin North Am 2017;31:435-53.

26. Schneider R, Cohen MJ, Benenson S, et al. Procalcitonin in hemodialysis patients presenting with fever or chills to the emergency department. Intern Emerg Med 2020;15:257-62.

27. Swede H, Hajduk AM, Sharma J, et al. Baseline serum C-reactive protein and death from colorectal cancer in the NHANES III cohort. Int J Cancer 2014;134:1862-70.

28. Wu P, Liang W, Chen X, et al. Pretransplant C-reactive protein as a prognostic marker in allogeneic stem cell transplantation: A PRISMA-compliant meta-analysis. Medicine (Baltimore) 2019;98:e14474.

Cite this article as: $\mathrm{Zu} \mathrm{DM}$, Zhang $\mathrm{L}$. Assessment of mechanisms of infectious pneumonia based on expression of fibrinogen, procalcitonin, high-sensitivity C-reactive protein expression, $\mathrm{T}$ helper 17 cells, regulatory $\mathrm{T}$ cells interleukin-10, and interleukin-17. Transl Pediatr 2022;11(1):73-84. doi: $10.21037 /$ tp-21-565
29. Li X, Chen Z. Correlation between serum levels of C-reactive protein and neonatal pneumonia: A protocol for systematic review and meta-analysis. Medicine (Baltimore) 2021;100:e25977.

30. Wang J, Wu X, Tian Y, et al. Dynamic changes and diagnostic and prognostic significance of serum PCT, hsCRP and s-100 protein in central nervous system infection. Exp Ther Med 2018;16:5156-60.

31. Liu C, Li Y, Chen Y, et al. Baicalein Restores the Balance of Th17/Treg Cells via Aryl Hydrocarbon Receptor to Attenuate Colitis. Mediators Inflamm 2020;2020:5918587.

32. Jia J, Zheng K, Shen H, et al. Qingchang Huashi granule ameliorates experimental colitis via restoring the dendritic cell-mediated Th17/Treg balance. BMC Complement Med Ther 2020;20:291.

33. Sharma A, Upadhyay DK, Gupta GD, et al. IL-23/Th17 Axis: A Potential Therapeutic Target of Psoriasis. Curr Drug Res Rev 2021. [Epub ahead of print]. doi: 10.2174/2 589977513666210707114520.

34. Kou W, Li X, Yao H, et al. Hypoxia disrupts aryl hydrocarbon receptor signaling and the Th17 response in allergic rhinitis patients. Mol Immunol 2018;101:364-9.

35. Wu H, Ding X, Zhao D, et al. Effect of montelukast combined with methylprednisolone for the treatment of mycoplasma pneumonia. J Int Med Res 2019;47:2555-61.

36. Akhmerov A, Rogers R, de Couto G, et al. Regulatory $\mathrm{T}$ cell activation, proliferation, and reprogramming induced by extracellular vesicles. J Heart Lung Transplant 2021;40:1387-95.

37. Di Giorgio E, Wang L, Xiong Y, et al. A Biological Circuit Involving Mef2c, Mef2d, and Hdac9 Controls the Immunosuppressive Functions of CD4+Foxp3+ T-Regulatory Cells. Front Immunol 2021;12:703632.

38. Szylberg Ł, Karbownik D, Marszałek A. The Role of FOXP3 in Human Cancers. Anticancer Res 2016;36:3789-94. 